\title{
Usos dos oráculos délficos em Plutarco
}

\author{
Uses in \\ Delphic oracles \\ of Plutarco
}

Maria Aparecida De Oliveira Silva

1 Nacionalidad: Brasileira. Grado: Doutora em História Social. Especialización: História Antiga. Adscripción: Departamento de Letras Clássicas e Vernáculas da Universidade de São Paulo.Correo electrónico: maosilva25@gmail.com; madsilva@usp.br 


\title{
REsumo
}

Desde o período arcaico grego, o santuário de Delfos recebeu consulentes gregos e bárbaros e, à época de Plutarco, encontramos registros de cidadãos romanos que recorreram ao deus Apolo para obterem suas respostas oraculares sobre as mais diversas questões. Assim, o objetivo deste capítulo é analisar a visão de Plutarco sobre a relação de gregos e romanos com os oráculos proferidos em Delfos.

Palaras-Chave: Plutarco, Delfos, Roma, Grécia.

\begin{abstract}
Since the Ancient Greek period the sanctuary of Delphi has received Greek and Barbarian consultants and records of Roman citizens who appealed to the god Apollo to obtain oracular answers about several subjects are found in the time Plutarch lived. Thus, the purpose of this chapter is to analyze Plutarch's view on the relationship between Greeks and Romans and the oracles of Delphi.
\end{abstract}

Key words: Plutarco, Delfos, Roma, Grécia. 


\section{Plutarco e Delfos}

7 stima-se que Plutarco tenha iniciado suas funções sacerdotais 1 em Delfos entre 95 e 100 d.C., época em que não mais exercia 1 cargos políticos, proferia palestras e ministrava cursos. Desde então, Plutarco manteve uma vida monástica e passou a redigir seus escritos com mais intensidade até o fim de sua vida. Plutarco relata seu sentimento de honra em ter servido Apolo Pítio como sacerdote em Delfos no tratado Se um Ancião Deve Engajar-se em Assuntos Públicos (792F). No Museu de Delfos, encontra-se preservado e aberto à exposição o célebre epigrama, um dístico, oferecido por délficos e queronenses a Plutarco, com a seguintes palavras:

\section{Delfos e queronenses ofertaram a Plutarco, obecedendo aos preceitos de Anfitrião ${ }^{1}$}

\section{(Dittenburger Syll $\left.{ }^{3} 843 \mathrm{~A}\right)$}

Embora o oráculo de Delfos represente o maior santuário religioso do mundo grego, não dispomos de relatos que dêem conta dos rituais e das práticas relacionadas a eles. No entanto, o santuário do deus Apolo atua como uma instituição não somente religiosa mas também política. Há incontáveis relatos de autores antigos que nos trazem as palavras proferidas em Delfos como motrizes de ações políticas no mundo grego. Convém lembrar que Heródoto nos informa que reis bárbaros também recorriam aos vates pítios, informação de que se vale Plutarco em seu tratado Da Malícia de Heródoto. Em um primeiro momento, causa-nos estranhamento ver que Plutarco defende Creso, um bárbaro, mas a análise do conteúdo de sua argumentação revela que, sob sua aparente defesa do rei da Lídia, nosso autor, na verdade, preocupa-se em atestar a pureza das oferendas recebidas em Delfos, como lemos no seguinte passo:

1 Tradução da autora. 
E Creso, quando coroado rei, matou um nobre, companheiro e amigo de Pantaleão, cortou-o em pedaços em um aparelho de tortura pontiagudo; e fez de suas riquezas oferendas que enviou aos deuses.

(Da Malícia de Heródoto, 858E-F)

Convém ressaltar que, uma vez verdadeira a afirmação herodotiana de que os objetos oferecidos ao deus por Creso eram de origem criminosa, o santuário de Delfos perderia seu caráter sagrado para se tornar um local de doações oriundas de atos sanguinários e ímpios, o que transformaria Delfos em um depósito de peças roubadas, um santuário maculado. Plutarco então afasta a hipótese de que o santuário seja rico em virtude dos atos de impiedade de seus beneméritos, já que Creso era reconhecidamente um grande benfeitor do santuário. Como ele próprio registra no passo abaixo:

A Creso, atesta nenhuma outra coisa bela que honrar os deuses com numerosas e suntuosas oferendas, e esse mesmo feito aponta ser o mais ímpio de todos.

\section{(Da Malícia de Heródoto, 858E)}

De fato, em Heródoto de Halicarnasso, encontramos esta descrição da relação de confiança e benemerência do rei lídio com o santuário:

Ao fazer oferenda aos délfios, Creso consultou o oráculo pela terceira vez. Efectivamente, desde que comprovou a verdade do oráculo, a ele recorria sem cessar.

(Histórias, I, 55)2

Em uma segunda análise, também notamos que a defesa de Creso representa a simpatia de Plutarco pelo rei, pois, ainda que bárbaro, ele

2 Tradução de José Ribeiro Ferreira e Maria de Fátima Silva, in: Heródoto, Histórias, Livro I, Lisboa: Edições 70, 2002. 
acredita na eficácia do santuário de Delfos e contribui para a riqueza do local. E, nessa altura de seu relato, podemos afirmar que Plutarco revela que Creso é um filogrego em contraposição a Heródoto, que se demonstra filobárbaro ao registrar ações consideradas ímpias contra um simpatizante da religiosidade grega, benfeitor do santuário mais importante do mundo grego. Também podemos fazer um paralelo com os imperadores romanos que consultavam o oráculo de Delfos, cujo nome mais proeminente era o de Adriano, que realizou inúmeras oferendas, além de ter patrocinado a reforma do local.

\section{Plutarco e o Oráculo}

Apesar de Plutarco ter sido sacerdote de Apolo em Delfos por mais de vinte anos, não há em seus escritos descrições sobre os ritos praticados durante a consulta do oráculo ou informações sobre as atividades desenvolvidas quotidianamente no santuário. Nosso autor faz numerosas referências aos oráculos em suas biografias e tratados, além de escrever três diretamente relacionados ao local, a saber, $D o$ $E$ de Delfos (384C-394C), Do Oráculo da Pítia (394D-409D) e Do Declínio dos Oráculos (409E-438D), formando o que denominamos de Tratados Délficos, datados entre 120 e 125 d.C., ou seja, escritos nos últimos anos de vida de Plutarco. Há ainda Dos que São Honrados pela Divindade (548A-568A), um tratado em forma de diálogo em que Plutarco registra um debate havido entre ele, o irmão Tímon, os amigos Pátrocles e Olímpico em Delfos, o qual não nos lega informações sobre os rituais praticados no santuário. Todos esses tratados são classificados pelos comentadores plutarquianos como escritos de natureza teológica e figuram ao lado dos remanescentes $D a$ Superstição (164E-171E), De Isis e Osiris (351C-384B) e Do Gênio de Sócrates (575A-598F). Há outros três listados no Catálogo de Lâmprias, dos quais nos restaram apenas fragmentos; são eles: Do Encanto da Mãe dos Deuses (no 140), Dos Dias Nefastos ( ${ }^{\circ}$ 150) e Das Esculturas de Dédalo em Plateia ( $\left.{ }^{\circ} 201\right)$. 
Em Do E de Delfos, Plutarco discorre sobre o significado do "E" posto na entrada do santuário, por causa da usual curiosidade sobre a pertinência de se ter colocado o "E" em Delfos, conforme lemos a seguir:

Há mais evidência de que os primeiros filósofos refletiram sobre a natureza do amado deus e o significado atribuído à letra "E", que é especial e importante, por isso quiseram apresentá-la como símbolo de alguma coisa grande. Eu tinha até agora evitado o assunto muitas vezes proposto em minha escola.

(Do E de Delfos, 385A)

Então, percebemos que Plutarco associa a filosofia à reflexão religiosa, em uma relação simbiótica em que a religiosidade do filósofo o inspira a verbalizar o divino, trazer para o mundo tangível o construto sensorial da religião, por isso ele afirma que Amônio fora instruído por Apolo, fato que legitima seu discurso. Convém lembrar que o deus Apolo está associado ao Sol, o que lhe confere uma natureza clara, luminosa, que o conduz à pureza, elemento essencial para o alcance da verdade3. Notamos que o mestre Amônio é a personagem utilizada por Plutarco para expressar seu entendimento da questão, porque "o deus não era menos filósofo que adivinho". Com esse argumento, Plutarco insere seu mestre Amônio no diálogo e, por meio dele, introduz o pensamento dos antigos filósofos gregos a respeito da simbologia de alguns elementos que jazem em Delfos, como a trípode, o sentido de Apolo e outros (385B). O cenário do diálogo é o próprio santuário em que estrangeiros interpelam Plutarco sobre o significado do "E" de Delfos.

O artifício retórico de Plutarco para fixar a atenção do ouvinte/ leitor em seu discurso manifesta-se em sua afirmação de que jamais respondera tal questão, nem mesmo para seus alunos. Após despertar o interesse de seu ouvinte/leitor, Plutarco explica que, por se tratar

3 Ver W. F. Otto, "Divindades gregas", in: Os deuses gregos: a imagem do divino na visão do espírito grego, tradução de Ordep Serra, São Paulo: Odysseus, 2005, p. 35-112. 
de estrangeiros prestes a partir, daria finalmente a esperada resposta (385A). Pela dinâmica de um diálogo, a resposta de Plutarco não é dada diretamente, pois outras personagens expressam suas opiniões; dentre elas, destacamos a do sacerdote Nicandro, que nos oferece a versão oficial de Delfos para o uso da letra "E". Conforme o referido sacerdote, a letra "E" corresponde à partícula interrogativa "ei"(se), com a qual se introduz perguntas aos deus Apolo, significando ao mesmo tempo uma partícula desiderativa, que reflete o sentimento de quem o consulta (392A). A resposta de Plutarco revela-se nas palavras de Amônio, que assim se pronuncia sobre o assunto:

Para mim, acho que a letra $\mathrm{E}$ não designa um número, nem ordem, nem um conjunto, nem qualquer parte do discurso, mas que em si é uma descrição perfeita do deus. Ela nos informa, por esse enunciado, força e virtude. $\mathrm{Na}$ verdade, quando nos aproximamos do santuário, o deus envia-nos estas palavras: "conhece-te a ti mesmo". E nós respondemos com o monossílabo: "Ei”, isto é, "Tu és”, e significa que atribuímos somente a ele a propriedade da verdade, única e incomunicável, que existe por si só.

(Do E de Delfos, 391E-392A)

Plutarco não desdiz o sacerdote, pois concorda com a expressão "Ei", mas nos apresenta uma versão diferente para a finalidade de sua inscrição no santuário, uma vez que "Ei” pode significar as duas coisas: "se" ou "és" são diferenciados apenas pela acentuação. Outro ponto concorde entre eles é que não se trata somente da letra "E", como vinham discutindo os pitagóricos, mas de uma expressão verbal do consulente, um sinal da interação entre o humano e o divino. Assim, para o nosso autor, ao consultar o oráculo de Delfos, o homem estabelece uma relação de confiança absoluta no que será pronunciado, o que legitima o processo, pois o ritual perderia vigor e sentido sem a fé do consultante.

No tratado Do Oráculo da Pítia, nosso autor constrói seu diálogo em torno do debate sobre a imperfeição linguística e métrica de mui- 
tos oráculos que são pronunciados em nome de Apolo, poetas e Musas (396D). A partir desse argumento, em debate com diversas personagens, Plutarco reflete sobre o processo de elaboração e expressão das palavras oraculares, permeada pela questão central posta na correlação que se estabelece entre o fim dos vates versificados e a decadência da mântica. Sob a égide do discurso de Filino, nosso autor responde ao seu antagonista Serapião - defensor da teoria de que o abandono dos versos responde pelo declínio dos oráculos -, com o seguinte parecer:

Excelente, Serapião! Você está certo. Não estamos abandonando a Filosofia, mas no caminho de sua aprovação do que foi produzido, pois os primeiros filósofos expressaram seus dogmas e teorias em versos, como Orfeu, Hesíodo, Parmênides, Empédocles, Tales. [...] Astronomia de novo: ela não foi rebaixada nas mãos de Aristarco, Timócares, Aristilo, Hiparco, toda escrita em prosa, ao passo que $\mathrm{Eu}^{-}$ doxo, Hesíodo e Tales usaram metros; se assumirmos que Tales realmente escreveu a Astronomia atribuída a ele. [...] Não é sem propósito e nem um absurdo para nós procurarmos as causas de tais mudanças, porque, para descartar qualquer uma das artes e das ciências em conjunto, só porque há alguma alteração ou variação em seus detalhes ou entrega, é algo totalmente injusto.

(Do Oráculo da Pítia, 396F-397A)

Plutarco nos revela habilidade retórica e influência do gênero dialógico, próprio de Platão, com a exposição de pensamentos dialéticos nas conversas travadas por suas personagens, demonstrando a fragilidade de argumentos construídos em dados infundados. Com relação aos outros diálogos compostos por Plutarco, Do Oráculo da Pítia inova com a inserção de uma segunda personagem: Téon, que atua como condutora de suas ideias. Em resposta ao dito sobre o abandono dos oráculos versificados, Plutarco endereça a Téon um extenso discurso, do qual extraímos as seguintes palavras: 
Quanto aos oráculos proferidos em nosso tempo, sabemos que muitos são realizados em prosa, mesmo antigamente, e que sempre atenderam questões de grande relevância.

(Do Oráculo da Pítia, 403A)

A personagem segue seu discurso argumentando que o oráculo versificado condiz mais com os tempos antigos, pois a sociedade de seu tempo cultua mais a simplicidade, a objetividade e o prosaico, uma vez que a linguagem cifrada dos oráculos permitia o engano e, com isso, criava um ambiente favorável ao surgimento de charlatães (403BC). Em seguida, Téon apresenta vários episódios em que os oráculos foram determinantes, afirmando que o decréscimo no número de consulentes está relacionado ao declínio populacional da Grécia de sua época e que se deve considerar a importância das questões levadas aos santuários, em geral, de cunho político (404B-404F). É interessante destacar que Plutarco condensa em sua análise a percepção histórica de que os versos pertencem a uma forma de expressão primeira da incipiente produção literária grega. Dessa maneira, os oráculos versificados supriam as expectativas de homens, inseridos em contextos histórico, social e literário específicos, que demandavam por tal gênero. Como Plutarco relatou anteriormente, o consulente estabelece um diálogo com a divindade que é intermediado pela Pítia, que, por sua vez, repassa o vate ao sacerdote, que finalmente o declara; portanto, o processo é entremeado por discursos de indivíduos que reproduzem a linguagem de seu tempo ${ }^{4}$.

Em Do Declínio dos Oráculos, Plutarco tece comentários sobre diversos assuntos relacionados à arte divinatória e, como o título destaca, destina suas principais reflexões a responder a complexa questão sobre as causas do declínio dos oráculos. Plutarco inicia seu diálogo narran-

4 Como notou Rocha Pereira, a discusão acerca da inspiração da Pítia e a veracidade de suas palavras são aspectos até hoje analisados por especialistas, que, da mesma forma deste diálogo, não atingiram resultados convincentes. Ver: M. H. Rocha Pereira, "Os Diálogos Píticos de Plutarco", in: Actas do Congresso "Plutarco Educador da Europa”, 11 e 12 de Novembro de 1999, Porto, Fundação Eng. António de Almeida, 2002, p. 39-41. 
do o mito da definição de Delfos como o centro do mundo. Em sua versão, duas águias ou dois cisnes foram lançados das extremidades da terra para determinar o seu centro. Tendo como premissa o ponto de encontro deles, tal marco foi sinalizado com uma pedra denominada ônfalo, que significa em português umbigo (409E-F). No mesmo lugar, foi construído o santuário de Apolo, e o altar em que se assentava a Pítia foi edificado ao lado da cônica pedra. A seguir, nosso autor afirma que há acontecimentos religiosos que Apolo declara incompreensíveis à razão humana e que assim deveriam permanecer, como mistérios divinos (409F).

Novamente mestre Amônio é a personagem principal do diálogo e portador das assertivas plutarquianas sobre o porquê do fechamento de diversos oráculos gregos, outrora famosos e muito frequentados. Como Plutarco adiantara no preâmbulo de sua obra, por intermédio de Amônio, a redução de consulentes e o consequente encerramento das atividades nos oráculos pertencem ao campo do divino nem sempre acessível ao entedimento humano, tal como lemos neste passo:

No entanto, atribuir o fechamento dos oráculos a qualquer outro poder que não à vontade de Apolo levantaria a suspeita de que esses oráculos nunca deveriam ter existido e não devem existir hoje, portanto, que teriam origens diferentes. Bem, lembre-se que nenhum poder superior, augusto, seria capaz de apagar e remover a adivinhação, pois a adivinhação é uma obra do deus. [...] Toda a obra divina deve ser maravilhosa e completa, livre de excesso, com capacidade suficiente de existir por ela própria. Esta é a persona que lhe convém, que é o princípio de que devemos aceitar como norma a soberania divina.

(Do Declínio dos Oráculos, 419A-B)

Então notamos que a inexplicabilidade dos acontecimentos atua como uma manobra retórica de Plutarco para que o leitor/ouvinte aceite de bom grado a sua explicação religiosa, sem fundamento lógico, de que a vontade divina é soberana. Dessa maneira, a soberania de Apolo justifica o encerramento das atividades de vários oráculos, por 
serem eles uma demonstração da vontade humana e não divina. Plutarco declara nas entrelinhas que o número de santuários era excessivo, daí nem todos representarem a divindade, mas atenderem às aspirações pessoais de um sacerdote que não possuía formação específica ${ }^{5}$.

Diante da falta de formação do sacerdote, justificam-se seus enganos, pois se trata de uma prática empírica, provavelmente desenvolvida por indivíduos que demonstram alguma afinidade com os rituais, com participações secundárias no início e, com o passar do tempo, fundam seus próprios santuários e os dedicam ao deus de sua escolha. Não importa a divindade para quem o sacerdote constrói o altar e o templo ou santuário, o processo divinatório é sempre regido por Apolo, por isso nosso autor justifica o desaparecimento de oráculos pela vontade do deus. Segundo Plutarco, o exímio arqueiro tem a precisão de suas flechas em seus vates6; quem os corrompe é a falibilidade humana do sacerdote ou da Pítia, que não são capazes de compreender por completo a fala de Apolo (Do Declínio dos Oráculos, 412C-E). Por sua declarada predileção pela filosofia platônica, manifestada em copiosas referências ao mestre platonista Amônio e às obras de Platão ao longo de toda a sua obra, podemos inferir que este passo d'A República influenciou seu pensamento:

- Então que é que nos resta ainda fazer em matéria de legislação?

- E eu respondi: - A nós, nada, mas a Apolo de Delfos competem as mais elevadas, mais belas e mais importante das disposições legais.

- Quais? - perguntou ele.

- A edificação de templos, sacrifícios e outros actos de culto aos deuses, divindades e heróis. E ainda a sepultura dos finados, e toda a assistência que deve prestar-se-lhes para tornar propícios os que estão no além. Sobre estes assuntos

5 Ver Walter Burkert, Religião grega na época clássica e arcaica, tradução de M. J. Simões Loureiro, Lisboa: Fundação Calouste Gulbenkian, 1993,p. 199-200.

6 Quanto à presença de sacerdotes de Apolo nos santuários de outros deuses; ver: Giulia Sissa e Marcel Detienne, Os deuses gregos, tradução de Rosa Maria Boaventura, São Paulo: Companhia das Letras, 1990, p. 217-232. 
nada sabemos, e ao fundarmos a cidade, a ninguém mais obedeceremos, se tivermos senso, nem seguiremos outro guia, senão o da nossa pátria. Pois sem dúvida é este deus que, em todos estes assuntos, é o intérprete nacional para todos os homens, quando profetiza sentado no omphalos, no centro da terra.

$$
\text { (A República, 392d e 394b-c) })^{7}
$$

Portanto, a vontade divina sempre prevalece sobre a humana, assertiva que norteia a resposta plutarquiana para a questão. É interessante perceber que a justificativa de Plutarco despedaça possíveis expectativas de quem aguardava uma alegação que o levasse a admitir o declínio da religiosidade dos gregos à época imperial. Pelo contrário, notamos em sua resposta que o fato é resultante de uma ação apolínea para ordenar os rituais divinatórios praticados em seu nome. Assim, em momento algum Plutarco reforça o afirmado anteriormente sobre a decadência dos oráculos, posto que também argumenta que os romanos de seu tempo consultavam o oráculo de Delfos (Do Oráculo da Pitia, 399B-C). Como demonstra Crippa, a distinção de Plutarco relativa ao tipo das respostas oraculares da Pítia permite-lhe abordar um problema mais amplo da adivinhação inspirada e de afirmar a autenticidade e o caráter sagrado da inspiração profética ${ }^{8}$.

\section{Conclusões}

Ao findar a exposição desses escritos, emerge a indagação sobre qual a motivação de Plutarco para escrever sobre o oráculo de Delfos, além de fazer referências a ele em outros tratados e em diversas de suas biografias. As respostas às perguntas de seus interlocutores representam ocasiões para Plutarco revelar aspectos importantes do santuário,

7 Tradução de Maria Helena da Rocha Pereira, in: Platão, República, Lisboa: Fundação Calouste Gulbenkian, 1993.

8 S. Crippa, "Introduction", in: Plutarque, Sur les oracles de la Pythie, texte établi e traduit par Robert Flacelière et introduction et notes par Sabina Crippa, Paris: Les Belles Lettres, 2007, p. XI. 
templo e altar de Apolo, assim como alguns dados sobre a atuação dos sacerdotes e da Pítia. No entanto, vemos que Plutarco conduz seus argumentos à compreensão de que havia romanos contrários a essas práticas divinatórias; tal como ele próprio registra, eram homens que ousavam atacar um local de glória milenar (Do Oráculo da Pítia, 408D).

Plutarco revela em seu discurso seu sentimento de pertença à cultura grega. Ainda que os romanos e seu invencível exército cerceassem os territórios e a política interna dos gregos, mostravam-se incapazes de controlar e até mesmo de destruir a tradicional cultura grega. Para Plutarco, a contrapartida da dominação romana na Grécia é sua convivência com uma comunidade que não renuncia a seu modo de ser grego.

\section{Bibliografia}

Fontes

Heródoto. Histórias. Livro I. Introdução geral de Maria Helena da Rocha Pereira. Introdução ao Livro I, versão do grego e notas de José Ribeiro Ferreira e Maria de Fátima Silva. Lisboa: Edições 70, 2002.

Platão. República. Introdução, tradução e notas de Maria Helena da Rocha Pereira. Lisboa: Fundação Calouste Gulbenkian, 1993.

Plutarch. How the Young Man Should Study Poetry. Moralia. Volume I. Translated by Frank Cole Babbitt. Cambridge/Massachusetts/ London: Harvard University Press, 2005.

. Isis and Osiris. Moralia. Volume V. Translated by Frank Cole Babbitt. Cambridge/Massachusetts/London: Harvard University Press, 1936.

. On Superstition. Moralia. Volume VII. Translated by Phillip H. de Lacy and Benedict Einarson. Cambridge/Massachusetts/London: Harvard University Press, 1959.

. The E at Delphi. Moralia. Volume V. Translated by Frank Cole Babbitt. Cambridge/Massachusetts/London: Harvard University Press, 1936. 
. The Malice of Herodotus. Translated with an Introduction and Commentary by Anthony J. Bowen. Warminster: Aris \& Phillips, 1992.

.The Oracles at Delphi No Longer Given in Verse. Moralia. Volume $V$. Translated by Frank Cole Babbitt. Cambridge/Massachusetts/ London: Harvard University Press, 1936.

. The Obsolescence of Oracles. Moralia. Volume V. Translated by Frank Cole Babbitt. Cambridge/Massachusetts/London: Harvard University Press, 1936.

.Whether an Old Man Should Engange in Public Affairs. Moralia. Volume $X$. Translated by Harold North Fowler. Cambridge/Massachusetts/London: Harvard University Press, 2002.

Plutarque. Sur les oracles de la Pythie. Texte établi e traduit par Robert Flacelière et introduction et notes par Sabina Crippa. Paris: Les Belles Lettres, 2007.

\section{Bibliografia citada}

Burkert, W. Religião grega na época clássica e arcaica. Tradução de M. J. Simões Loureiro. Lisboa: Fundação Calouste Gulbenkian, 1993.

Crippa, S. “Introduction”. In: Plutarque. Sur les oracles de la Pytbie. Texte établi e traduit par Robert Flacelière et introduction et notes par Sabina Crippa. Paris: Les Belles Lettres, 2007, p. VII-XXVII.

Dittenburger, W. \& Purgold, K. Die Inschriften von Delphi. Berlin: 1896.

Froidefond, C. "Plutarque et le platonisme". ANRW. II, 36.1, 1987, p. $185-233$.

Grimal, P. A cidades romanas. Tradução de António Lopes Rodrigues. Lisboa: Edições 70, 2003.

Grube, G. M. A. The Greek and Roman Critics. Great Britain: Methuem, 1965.

Jones, C. P. "The Teacher of Plutarch". Harvard Studies in Classical Philology. Volume 71, 1967, p. 205-213. 
Otto, W. F. "Divindades gregas". In: Os deuses gregos: a imagem do divino na visão do espírito grego. Tradução de Ordep Serra. São Paulo: Odysseus, 2005, p. 35-112.

Pérez Jiménez, A. "Introducción general". In: Vidas Paralelas I. Madrid: Gredos, 1985, p. 7-135.

Puech, B. "Prosopographie des amis de Plutarque". ANRW. Band 33.6, 1992, p. 4829-4893.

Rocha Pereira, M. H. "Os Diálogos Píticos de Plutarco". In: Actas do Congresso "Plutarco Educador da Europa", 11 e 12 de Novembro de 1999. Porto: Fundação Eng. António de Almeida, 2002, p. 29-43.

Roskam, G. "Plutarch on Self and Others". Ancient Society. Volume 34, 2004, p. 245-273.

Sissa, G. e Detienne, M. Os deuses gregos. Tradução de Rosa Maria Boaventura. São Paulo: Companhia das Letras, 1990.

Stadter, P. A. “Plutarch: Diplomat for Delphi?”. In: De Blois, L.; Bons, J.; Kessels, T. e Schenkeveld, D. M. (Eds.). “Volume I: Plutarch's Statesman and his Aftermath: Political, Philosophical, and Literary Aspects. Proceedings of the Sixth International Conference of the International Plutarch Society. Nijmegen/Castle Hernen, May 1-5, 2002". Mnemosyne, Supplementum 250, 2004, p. 19-31.

Willamowitz-Moellendorff, U. "Plutarch as a Biographer".In: SCARDIGLI, B. (Ed.). Essays on Plutarch's Lives. Oxford: Clarendon Press, 1995, p. 47-74.

Ziegler, K. "Plutarchos von Chaironeia". Paulys Real-Encyclopädie der Klassischen Altertumswissenschaft. Stuttgart: Verlag, 1951, cols. 636-962. 